\title{
Enfoques psicoanalíticos para los problemas en la vida. Una síntesis ${ }^{1}$
}

\author{
Sandra Buechler, Ph.D. ${ }^{2}$ \\ New York, USA
}

Este trabajo resume el esfuerzo de muchos años en que la autora ha estado tratando de descifrar cómo (los psicoterapeutas) ayudamos a las personas a hacer frente a las dificultades que enfrentan en sus vidas. La vida nos presenta a todos desafíos, y nuestro trabajo es ayudar a nuestros pacientes a enfrentar esos desafíos tan bien como puedan. Entre los principales desafíos está necesidad humana de poder conectarse con los demás y poder estar separado de ellos, como una única capacidad; la capacidad de expresar nuestro sufrimiento cuando soportamos una gran pérdida; y entre esas pérdidas, nuestra capacidad para afrontar el envejecimiento. También como superar intensos sentimientos de vergüenza, humillación y culpa, que les están haciendo a las personas sentir insuficientes e inadecuadas. Concluye resaltando el valor de la verdad y la importancia vital de la integridad como valores cruciales que debemos transmitir en la formación de los psicoterapeutas.

Palabras clave: Necesidades humanas, problemas de la vida, pena, envejecimiento, vergüenza, culpa, Integridad.

This paper summarizes the effort of many years in which the author has been trying to decipher how (psychotherapists) we help people to face the difficulties they face in their lives. Life presents us with all challenges, and our job is to help our patients face those challenges as well as they can. Among the main challenges is human need to be able to connect with others and to be separated from them, as a single capacity; the ability to express our suffering when we bear a great loss; and among those losses, our ability to cope with aging. Also how to overcome intense feelings of shame, humiliation and guilt, which are making people feel insufficient and inadequate. It concludes by highlighting the value of truth and the vital importance of integrity as crucial values that we must transmit in the training of psychotherapists.

Key Words: Human needs, life' problems, grief, aging, shame, guilt, integrity.

English Title: Psychoanalytic approaches to problems in life. A synthesis

\section{Cita bibliográfica / Reference citation:}

Buechler, S. (2020). Enfoques psicoanalíticos para los problemas de la vida. Una síntesis. Clínica e Investigación Relacional, 14 (1): 185-202. [ISSN 1988-2939] [Recuperado de www.ceir.info ] DOI: 10.21110/19882939.2020.1401011

\footnotetext{
${ }^{1}$ Texto preparado para su intervención en Ágora Relacional-IPR, Madrid el 3 de Febrero de 2020. Traducción castellana de Alejandro Ávila Espada, revisada por Sandra Toribio Caballero (Instituto de Psicoterapia Relacional). Las menciones que hace la autora hacen referencia a su última obra: Buechler, S. (2019). Psychoanalytic approaches to problems in living. Addressing life's changes in clinical practice. New York: Routledge

2 Sandra Buechler, Ph.D. (New York) es Psicoanalista, Analista Didacta y Supervisora en el William Alanson White Institute y supervisora en el Programa postdoctoral y de Residentes del Columbia Presbyterian Hospital, así como en el Institute for Contemporary Psychotherapy. Entre sus obras: Valores de la Clínica: Emociones que guían el tratamiento psicoanalítico (2004); Marcando la diferencia en las vidas de los pacientes: Experiencia emocional en el ámbito terapéutico (2008); Permanezco ejerciendo: Las alegrías y angustias de una carrera clínica (2012); Comprendiendo y tratando pacientes en Psicoanálisis Clínico: Lecciones desde la Literatura (2015); Reflexiones psicoanalíticas. Formación y práctica (2018) y La aproximación psicoanalítica a los problemas del vivir (2019).
} 
Es un gran placer estar de nuevo aquí, y hablar con ustedes esta noche. Mi tema hoy son los enfoques psicoanalíticos de los problemas de la vida. Desde hace muchos años he estado tratando de descifrar cómo ayudamos a las personas a hacer frente a las dificultades que enfrentan en sus vidas. Este es mi tema. La vida nos presenta a todos desafíos, y nuestro trabajo es ayudar a nuestros pacientes a enfrentar esos desafíos tan bien como puedan.

El primer problema que abordo es la necesidad humana de poder conectarse con los demás y poder estar separado de ellos. Considero esto como una sola capacidad, la capacidad de relación y soledad. En otras palabras, el individuo seguro se siente lo suficientemente seguro como para estar solo y lo suficientemente seguro como para crear una relación. Tal persona sabe que no tendrá que fusionarse con la otra persona o huir de la otra persona, ni siquiera cuando las cosas van mal en la relación. Son capaces de soportar tanto la soledad como la relación, porque, en sus primeros años de vida, fueron capaces de interiorizar un objeto lo suficientemente bueno que ahora los llena y les da una base segura. Otra manera de decir esto es que la persona segura no necesita mirar fuera de sí misma, o ella misma ser completada por otra persona, por lo que son más capaces de seguir amando incluso cuando el otro les falla. Esta plenitud interior permite a la persona segura estar cómoda sola $¥$ cómoda con otra persona. Una capacidad relacionada es la capacidad de seguir amando la vida. En mi propio idioma, una de nuestras mayores tareas es "amar la vida de todos modos." Lo que quiero decir con eso es que nuestra relación con la vida misma debe ser capaz de resistir lo que nos suceda. Tenemos que ser capaces de aferrarnos a un amor por la vida sin importar lo que la vida nos haga.

Así que el primer gran desafío humano es estar lo suficientemente seguro como para amar a otra persona, y ser capaz de soportar estar solo, y ser capaz de aferrarse al amor por la vida. ¿Cómo ayudamos a las personas a desarrollar esta fuerza si vienen al tratamiento sin ella? Sugiero que una forma en que suceda es que proporcionamos una experiencia de proximidad sin intrusión, que es análoga a la madre lo suficientemente buena en el pensamiento de Winnicott. En otras palabras, estamos allí, podemos ser alcanzados, pero también estamos dejando que el paciente tenga su propio espacio y no nos entrometamos en su espacio. Si proporcionamos esto, y entonces el paciente nos interioriza, su mundo interno cambia y se vuelve más seguro. Nos convertimos en un aliado internalizado. En otras palabras, tiene que ser lo suficientemente significativo como para que le llegue al paciente $y$, una vez interiorizado, lo suficientemente poderoso como para cambiar realmente cómo se siente el mundo. Con este cambio en el mundo interno, el paciente puede llegar a ser capaz de estar con otra persona sin tener que fusionarse con ellos por seguridad o huir de ellos por 
seguridad. Son lo suficientemente seguros como para amar a otra persona, y lo suficientemente fuertes como para soportar tiempos en los que está sola, y también están lo suficientemente unidos a la vida misma a las dificultades climáticas, las penas, el dolor y aún así aman la vida.

Esto me lleva a un segundo gran desafío, en el segundo capítulo de mi libro, la capacidad de llorar cuando soportamos una gran pérdida. Permítanme leer un gran poema, de Mary Oliver.

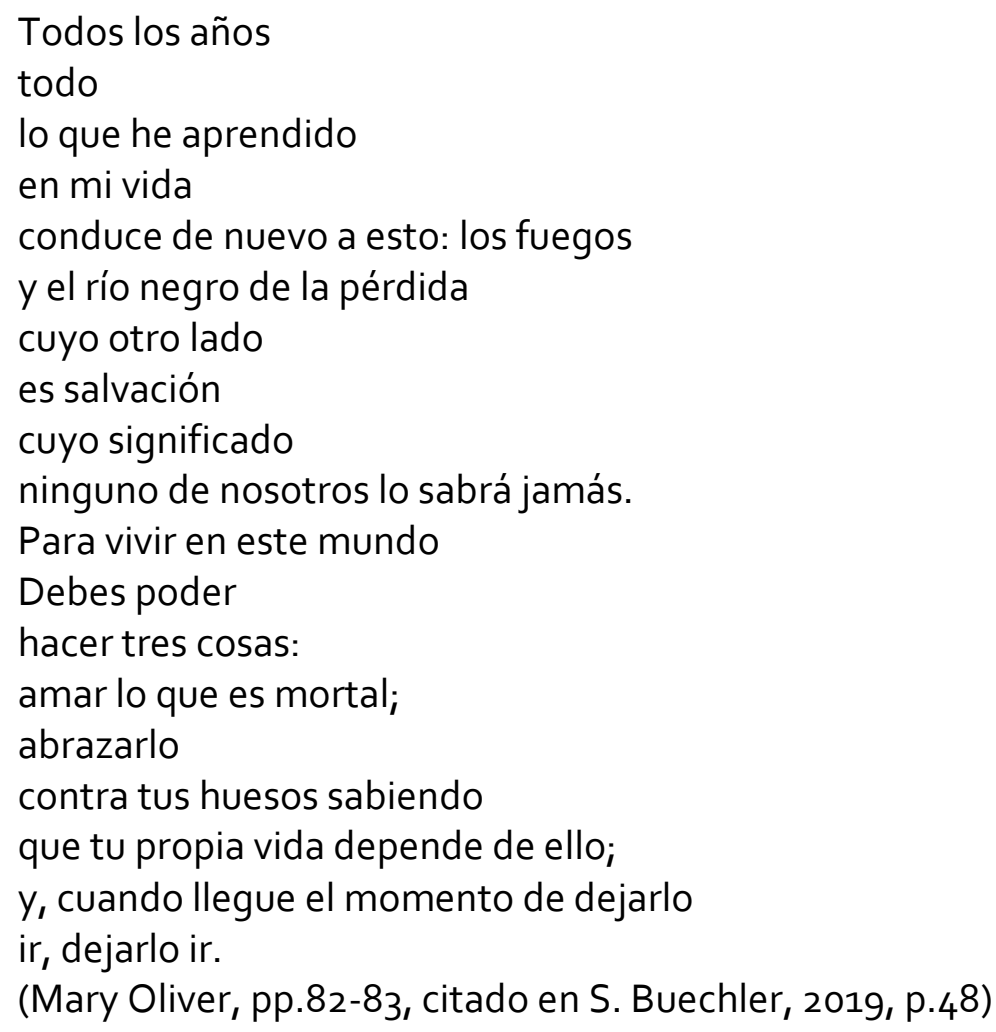

¡Qué hermosa expresión de uno de los desafíos más difíciles de la vida! Amar a eso de lo que depende nuestra vida, de lo que sabemos que perderemos $y$, sin embargo, lo sujetaremos firmes y cercano a nosotros. Y luego, cuando llegue la pérdida, dejarla ir. ¿Qué nos puede dar esta fuerza y cómo podemos ayudar a nuestros pacientes a desarrollarla?

En este capítulo de mi libro, hablo de algunas de las maneras en la que creo que los analistas, filósofos y otros han malinterpretado lo que se necesita para soportar la pena. La idea de que el duelo tiene etapas separadas y podemos pasar por ellas al igual que subimos un juego de escaleras es, para mí, equivocada y engañosa. Aún peor que engañar, avergüenza a los dolientes que no se experimentan a sí mismos como progresando de una etapa a la siguiente. 
Otra descripción falsa, desde mi punto de vista, es el ideal propuesto por algunos estoicos, de que debemos alejarnos del dolor lo más rápido posible. Esto es lo que escribí sobre ese enfoque.

Taylor describe la respuesta "saludable" a la adversidad como un sentimiento de orgullo que privilegia la fortaleza de uno mismo sobre las expresiones emocionales de dolor. Escribe sobre la "gran prueba" de responder a la "muerte de un hijo o hija que era inteligente y fuerte, y lleno de promesas de grandes logros" (p.103). Taylor contrasta una respuesta fuerte y noble con la reacción de aquellos que "se colapsan en gemidos y autocompasión" (p.103). En mi comentario sobre esta declaración, dije que reprobaría la mayor parte de la propuesta de Taylor.

Incluso si un hijo o una hija mía no fueran excepcionalmente inteligentes, fuertes o llenos de promesas, a su muerte ciertamente lloraría y haría mucho más. El lenguaje de Taylor contrasta la nobleza, en un extremo de un espectro, con la autocompasión gimoteante en el otro. Lo que él eleva como saludable orgullo y fortaleza lo veo como una especie de narcisismo esquizoide. (Buechler, 2010, pp.341-342)

También sugerí que este enfoque puede tener el efecto contrario al previsto. Por ejemplo, si influimos en un paciente para silenciar el dolor, puede perder su potencial positivo, es decir la posibilidad, en un estado de dolor, de conectarse con otros que ofrecen empatía. (S. Buechler, 2019, p.45).

Mi actitud sobre el dolor proviene de mis propias experiencias personales, así como de mis experiencias como clínica, y de la teoría de las emociones. Creo que la tristeza por una pérdida significativa puede durar toda la vida, y no ser patológica. Aunque me encanta el artículo de Freud sobre el Duelo y la melancolía, discrepo con él de dos maneras importantes. Por un lado, creo que Freud privilegia el "superar" el dolor, porque él cree que sólo tenemos una cantidad limitada de catexis, y así, para poder estar involucrados con nuevos objetos tenemos que renunciar al apego al objeto perdido. No estoy de acuerdo con esto. No creo que el amor sea finito. Seguir amando a alguien que murió no me impide amar a otras personas. Por el contrario, creo que el amor aumenta nuestra capacidad de amar a los demás. Y también estoy en desacuerdo con la idea de Freud de que la principal complicación del dolor, que puede convertir el dolor en depresión, es la ambivalencia hacia el objeto. Freud está enfatizando las emociones relacionadas con la ira a expensas de otras, igualmente importantes, en mi opinión. Creo que el dolor puede ser complicado, puede convertirse en depresión, debido a muchas otras emociones además de la ambivalencia hacia la persona 
que perdimos. Por ejemplo, creo que los remordimientos complican el dolor más a menudo que la ambivalencia.

Como clínicos, creo que es importante reconocer que la tristeza es una respuesta normal a la pérdida, que no es útil hacer que el doliente se sienta avergonzado de su dolor, o inadecuado por seguir sintiéndolo. El dolor puede tener algunos usos constructivos, como ayudarnos a conectar con los demás, ya que todos los seres humanos conocen la tristeza. Pero no hay dos personas que lloren exactamente de la misma manera, ya que cada uno de nosotros trae toda nuestra historia de tristezas a cada nueva pérdida. Cuando la gente dice que siente tu dolor, esto no es cierto. Pueden sentir una emoción propia que es evocada por tu dolor, pero nadie puede sentir exactamente lo mismo que tú. Esto plantea muchas preguntas acerca de lo que es verdaderamente empático, en respuesta al dolor de alguien. Creo que la tristeza es inherentemente aislante, es decir, siempre nos sentimos un poco solos en ella. Nadie más puede conocer nuestro dolor plenamente, por muy bien intencionados que sean. Para mí, el dolor debe ser respetado y acompañado. Creo que es lo mejor que cualquiera puede hacer, incluso el analista muy capaz y bien intencionado.

En cierto modo, hay superposición entre los desafíos del duelo (capítulo 2) y los desafíos del envejecimiento (capítulo 3). Ambos implican pérdidas y ambos son partes normales e inevitables de la vida. Las actitudes del clínico sobre el envejecimiento inevitablemente desempeñarán un papel en su trabajo. Una de mis creencias más firmes sobre ser analista es que nuestro trabajo se ve inevitablemente afectado por lo que somos como personas. Cómo nos centramos en el material, lo que, para nosotros, es lo suficientemente importante como para recordar, responder, pensar, etc., es parcialmente un producto de lo que somos. No importa cuánto creamos ser una pantalla en blanco, nunca podremos serlo. Así, por ejemplo, nuestras propias actitudes sobre lo que significa envejecer inevitablemente afectarán nuestro trabajo.

Me gustaría leer algunos párrafos de mi capítulo sobre el envejecimiento, para darles una idea de algunas de las cuestiones importantes, desde mi perspectiva.

¿Cómo podemos ayudar a las personas a navegar por el envejecimiento y a acercarse a la muerte? Este capítulo presenta primero algunos de sus desafíos inherentes. Creo que es especialmente interesante observar cuestiones que parecen evocar regularmente consejos contradictorios por parte de los comentaristas. Por ejemplo, ¿deberíamos luchar contra el envejecimiento, aferrándonos a nuestro estado actual con todas nuestras fuerzas? ¿O es mejor, en cierto sentido "más saludable", adaptarse felizmente? Las actitudes acerca de la adaptación y la intensidad emocional influyen en cómo cada uno de nosotros quiere abordar 
nuestro propio envejecimiento y muerte. ¿Vemos la muerte como más soportable si disminuimos o tratamos de mantener nuestras inversiones en la vida hasta el final? ¿Creemos que estaremos mejor si enfocamos nuestra atención en el pasado, presente o futuro? A medida que envejecemos, ¿es hora de liberarnos de las convenciones? ¿Qué causa la vergüenza y el disgusto por el envejecimiento? ¿Cómo se tiñe el envejecimiento por los patrones defensivos de por vida del individuo? ¿Cómo pueden aquellos de edad avanzada soportar mejor su envidia de los jóvenes? Por supuesto, estas preguntas se expresan como opciones para mayor claridad. Cada una es un conjunto mucho más complicado de problemas conscientes y no conscientes. (p.50)

¿Deberíamos "ser dóciles, dejarnos llevar dócilmente"? ¿O deberíamos "enfurecernos contra la muerte de la luz"? ¿En qué se puede traducir cada una de estas actitudes en el comportamiento? En términos más generales, ¿cómo ayudamos a las personas a vivir el envejecimiento lo mejor posible? Para cada uno de nosotros, nuestra actitud general acerca de adaptarnos a nosotros mismos para adaptarnos fácilmente a nuestras circunstancias impacta nuestro enfoque, también en todos los demás aspectos, los partícipes del tratamiento muestran sus sentimientos sobre la adaptación (generalmente fuera de su conciencia). Este es un tema que exploro en cada capítulo o en todo este libro.

Mientras lo leo, el poema de Dylan Thomas contiene toda una filosofía de vida. Nos exhorta a bajar a pelear. Otros dirían que sería mejor aceptarlo con gracia, gradualmente aceptar lo inevitable. Thomas opta por lo primero $y$, al menos en mi entendimiento, sugiere lo que podría hacer que la muerte sea particularmente insoportable.

Aunque los sabios entienden al final que la oscuridad es lo correcto, Como a su verbo ningún rayo a confiado vigor

No entran dócilmente en esa buena noche Llorando los hombres buenos, al llegar la última ola

Por el brillo con que sus frágiles obras pudieron haber danzado en una verde bahía

Se enfurecen, se enfurecen ante la muerte de luz.

(D. Thomas, 2010.p.19)

Incluso los sabios no pueden aceptar lo inevitable e irse en silencio cuando tienen que soportar pesares profundos. Si la vida no nos dio una oportunidad justa para brillar, o la sabiduría llegó demasiado tarde, y sentimos que no hemos aprovechado al máximo nuestros talentos, la muerte es demasiado dolorosa para aceptarla. (S. Buechler, 2019, p.51) 
Y tú, mi padre, allí en la triste altura,

Maldición, bendíceme ahora, con tus lágrimas feroces, rezo,

No entres suavemente en esa buena noche.

Rabia, rabia contra la muerte de la luz.

(p.19)

Estoy segura de que hay muchas maneras de entender estas líneas. Para mí, expresan el deseo del autor de evitar el dolor de ver en su padre al final de la vida una respuesta vencida y emocionalmente silenciada. Le ruega a su padre un legado memorable. Ya sea que las lágrimas del padre lo maldigan o lo bendigan, importa menos si quien lo emite es un hombre que es feroz, vital, apasionado hasta el último aliento. No quiere que el apego de su padre a la vida sea débil y tenue. Quiere recordarlo con toda su intensidad. Importa menos si es un padre amoroso u odioso, siempre que sea un padre lleno de vida. (S. Buechler, 2019, p.52)

Ahora llego a un capítulo, el capítulo cuatro, que es realmente el corazón del libro. Se trata de la cuestión de cómo los seres humanos pueden tener suficiente resiliencia para soportar las dificultades de la vida y seguir vivos.

El 8 de enero de 2017, en la revista del New York Times, Jan Mooallem publicó y tituló el artículo "La casa en el fin del mundo". Es la historia de un estudiante universitario llamado B.J. Miller que salió a tomar unos tragos con amigos y tuvo un terrible accidente que lo llevó a una unidad de quemados, cerca de la muerte. Perdió ambas piernas y un brazo justo debajo del codo. Cuando Miller salió de la cirugía, le dijo a su madre, que estaba en silla de ruedas, que ahora tenían más en común. Según el artículo, Miller no experimentó repentinamente un estado de claridad espiritual. Más bien, sintió que estaba en una tremenda confusión. Pero, mirando hacia atrás en ese momento, Miller siente que encontró una buena perspectiva de su situación, y estaba decidido a fingir esa actitud hasta que realmente pudiera sentirla. Desde el punto de vista de Miller, él no es diferente de los demás, ya que cada vida humana, incluida la suya, es difícil en su propia forma única.

Podría llamar a esto un enfoque de "fingirlo hasta que lo consigas" para cultivar la resiliencia. Por supuesto, esto no es psicoanálisis, pero creo que es muy interesante contrastarlo con los valores que muchos analistas tienen implícitamente. Mi objetivo es explorar $y$, en algunos casos, desafiar los valores sobre la resiliencia saludable que creo que están integrados en nuestras teorías y en el trabajo clínico que hacemos.

Miller se veía a sí mismo en algún lugar en un continuo entre una persona en su lecho de muerte y alguien que había perdido las llaves de su auto. Él creía que, por error, tratamos el sufrimiento como una interrupción de la vida que se supone que tenemos, en lugar de ser 
una parte inevitable de la vida. Miller dice que trató de meterse en esas lesiones, en lugar de superarlas, ya que considera que la profesión médica lo recomienda implícitamente. ¿Qué actitud hacia el sufrimiento tiene nuestra profesión psicoanalítica? (S. Buechler, 2019, p.73)

Me sorprende que Miller fuera a la Facultad de Medicina y ahora dirija un Hospital de Cuidados Paliativos en California que ayude a las personas que están muriendo a encontrar su propia manera personal de enfrentar la muerte. Creo que su historia trae algunos de los temas más importantes para el clínico. ¿Cómo podemos ayudar a la gente a encontrar algo como la fuerza que Miller tenía que tener? Lo más importante para mí es que seamos conscientes de las actitudes, tomadas de la cultura psicoanalítica, de la cultura más amplia y de nuestra propia experiencia, que en realidad nos impiden ser útiles. Algunos ejemplos, desde mi punto de vista, incluyen la idea de que se puede evitar el sufrimiento, o que siempre es importante confrontar las defensas, incluso cuando esas defensas podrían estar ayudando al paciente a soportar una situación tremendamente difícil, o que la gente siempre debe ser capaz de hablar sobre el futuro, o que toda la perspicacia tiene que ser verbalizada para ser eficaz. Creo que debemos tratar de ser conscientes de nuestras suposiciones sobre el sufrimiento, y cuestionarlas dentro de nosotros mismos.

A veces, ser capaz de ver el progreso en un cambio muy pequeño ayuda a alguien a seguir intentándolo e inspira la esperanza de más cambio. Pero para poder aceptar esta actitud, tal vez tengamos que dejar de lado nuestras propias suposiciones preexistentes sobre lo que debe suceder. Una vez más, hay una mezcla de adaptación a la realidad y, al mismo tiempo, trabajamos duro para lograr un mejor resultado, que creo que tenemos que cultivar en nosotros mismos antes de poder ayudar a nuestros pacientes. Aquí hay una situación en la que tuve que aprender esto por mí misma.

Cuando tenía unos 30 años, tomé un trabajo que implicaba una buena oferta de consultoría en una amplia variedad de hospitales y clínicas. Como parte de mis responsabilidades, ejercí la consulta en un "hospital" en una zona rural. En esta comunidad el incesto era común, lo que derivó en algunos niños nacidos con múltiples discapacidades mentales y físicas extremadamente graves que serían raros en una población más típica. Pero llamarlo hospital glorifica lo que realmente era, apenas un almacén donde los cuerpos de los bebés terriblemente malformados genéticamente estaban almacenados, convenientemente lejos de la vista de sus padres. Mi misión era ayudar a las enfermeras del pabellón donde se guardaban los bebés hidrocéfalos. Estos bebés, que generalmente vivían sólo semanas, tenían cabezas distorsionadas casi tan grandes como sus camas. Su "más alta" respuesta intelectual era un parpadeo ocular. No se me escapó la ironía de que me asignaran para ayudar a estas enfermeras veteranas a afrontarlo. Me resultó muy difícil mirar a estos bebés. 
Apenas podía llegar al pabellón, y las enfermeras a las que debía ayudar sobrevivían allí haciendo turnos de 8 horas. Sin embargo, pude ser de ayuda al focalizarme en las enfermeras, y ocupar mi mente imaginando lo que permitió a algunas sobrevivir mejor que otras. En otras palabras, usé mi mente para tratar de crear una tarea que tuve alguna oportunidad de lograr. Tuve que hacer esto. Y luego noté algo. Las enfermeras que eran más capaces de hacer frente parecían ser las que vieron progresos en la respuesta de parpadeo ocular más minúscula en el ojo de los bebés. Aquellos que vieron, en el ojo parpadeos, algo que significaba que los bebés estaban "aprendiendo" o "respondiendo al entorno", o "desarrollando un apego a ellos" me pareció que eran capaces de lidiar mejor con su trabajo. Por supuesto, nunca sabré ninguna verdad objetiva sobre si los ojos de estos bebés tenían los significados que las enfermeras les atribuyen. Pero estas enfermeras habían desarrollado una manera honesta de hacer frente a esa realidad, en el sentido de que no pensaban que los bebés iban a ser capaces de hablar, o incluso vivir mucho tiempo, pero, en realidad, encontraron una meta, en este caso un parpadeo ocular que significaba que eran en cierto sentido un ser humano receptivo cuya experiencia interior importaba. No sé si ayudé a alguna de las enfermeras, pero sí sé que me enseñaron una valiosa lección, una lección que es igual de importante para hacer un tratamiento psicoanalítico tres veces a la semana de un adulto altamente competente como lo fue para las enfermeras que cuidan a los bebés hidrocéfalos. Tenemos que ser flexibles en la forma en que definimos el progreso.

Como clínicos, también creo que a veces fomentamos la fuerza del paciente ayudándoles a encontrar palabras para su experiencia, y desarrollando un lenguaje con ellos que ambos entendemos. Así es como escribí sobre este proceso.

He escrito en otra parte (Buechler, 2004) sobre mi trabajo con un paciente al que llamo "John". Había sido dado de alta de un hospital estatal y lo traté en nuestra clínica ambulatoria. Su historia estuvo plagada de un profundo abandono. Su tono era realista, carente de afecto. La vida de John estaba marcada por rituales. Se aseguró de que no se sintiera muy cómodo durmiendo haciendo sonar la alarma cada pocas horas. Se impidió disfrutar de lavarse el cabello, al hacerlo con agua helada.

Era apenas mayor que John cuando comencé a verlo, en un tratamiento que duró cuatro años. Fue mi primer trabajo profesional, y todavía estaba en la escuela de postgrado. Realmente no tenía idea de cómo ayudarlo. Pero cuando me contó una experiencia, en su tono seco y sin emociones, adiviné lo que podría haber estado sintiendo. Sentí el afecto que faltaba. Unos años después de iniciar el trabajo, John comenzó a decirme algo que sucedió con la frase, "Dirías que me sentí ..." (ansioso o enojado, no recuerdo cuál). Esto me conmovió mucho, sabiendo, de alguna incipiente manera, que esto era un progreso. Ahora, 
también diría que era similar a la poesía, ya que marcaba y creaba un cambio al mismo tiempo. Expresaba la creciente conciencia de John de mí como una persona separada con mi propia subjetividad. Pero las palabras también se movieron hacia la creación del abanico "nosotros". Entendimos que yo suministraba palabras cargadas de afecto. Este fue un momento mágico, para mí. Creo que, en cierto modo, fue el momento en que me convertí en clínica. Comprendí cuánto pueden importar las palabras y cómo, a veces, en realidad pueden cambiar la realidad. (S. Buechler, 2019, pp. 88-89)

No creo que fomentar la resiliencia siempre tome esta forma. A veces, la comprensión sin palabras es igual de significativa o incluso más significativa. Así es como elaboré una visión de Erich Fromm.

Las palabras pueden dar al hablante y al oyente una falsa sensación de que se entiende una experiencia. Si hubiera etiquetado un trozo de tela como "rojo", ¿eso significa que estamos teniendo la misma experiencia? Erich Fromm (2009) ha argumentado elocuentemente que las palabras en realidad pueden alienarnos de las experiencias vividas.

En realidad, si se pronuncia una Palabra, al pronunciar la Palabra, ya se aleja de la experiencia. La experiencia está realmente allí, solo un momento antes de que digas la Palabra. Una vez que se dice la Palabra, ya está allí. (p.14)

Muchos pacientes se quejan de la expectativa de que tienen que usar palabras para participar en la "curación por la palabra". Los analistas a menudo experimentan (e interpretan) el silencio del paciente como una forma de resistencia. Pero creo que el silencio también puede representar la sensación del paciente (a pesar de que pueda ser incipiente) de que no hay palabras que sean adecuadas para transmitir lo que sienten. En algunas situaciones, la voluntad del analista de esperar a que el paciente encuentre palabras, por mucho tiempo que sea, puede ser el mejor regalo posible. A veces he sentido que puedo honrar mejor la experiencia del paciente al no insistir en las palabras. Las palabras pronunciadas pueden hacerme sentir (relativamente) cómoda e instalada en mi rol analítico familiar. Son, en algunos sentidos, mi hogar. ¿Qué pasa si no son del paciente?

Suponemos que, si el paciente tiene palabras que se ajustan a su experiencia, esto fomenta una visión curativa. Sin duda eso es con frecuencia cierto. Encontrar palabras puede convencer al paciente de que lo que él o ella siente ahora, se ha sentido antes y se ha transmitido adecuadamente. Esto bien puede evocar la fuerza que requiere la resiliencia, pero creo que no disminuye el valor de las (experiencias) no articuladas. (S. Buechler, 2019, pp. 89-90) 
Voy a saltarme los próximos dos capítulos, en aras de la síntesis. Tratan de cómo el clínico puede tener fuertes convicciones y seguir siendo consciente de nuestra subjetividad inherente e inevitable, y cómo podemos ayudar a las personas que tienen problemas en el área de su vida laboral.

En el capítulo 7, hablo de ayudar a las personas a superar intensos sentimientos de vergüenza, humillación y culpa, que las están haciendo sentir insuficientes e inadecuadas. Normalmente distingo la verguenza y la culpa con una historia. Si suspendiste un examen a pesar de que estudiaste, podrías sentir vergüenza por tu "insuficiencia". Pero si no estudiaste, pero crees que deberías haberlo hecho, podrías sentir culpa.

La vergüenza puede ser mortal. La gente muere por ella cada día. Un objetivo del tratamiento puede ser ayudar al paciente a valorar la vida sobre el orgullo, a preocuparse más por la calidad de su experiencia que por lo exitosa que pueda parecer su vida. A menudo, las primeras fases del tratamiento implican suavizar las duras demandas y juicios del superego. Pero los seres humanos no pueden prescindir del todo sin sentir a veces culpa, que puede funcionar para evitar que dañemos a los demás.

Este es un ejemplo clínico que me afectó profundamente.

Este desafío me recuerda la sensación de hundimiento que sentí, hace muchos años, al sentarme con una de mis pacientes, una mujer que estaba confinada en una silla de ruedas. (He escrito sobre mi trabajo con esta mujer en una publicación anterior [Buechler, 2000/2017]). Su ira hacia mí no conocía límites. ¿Por qué, me preguntaba, Sandra Buechler merece dos buenas piernas y la oportunidad de tener lo que sea y a quien ella quiera? En una sesión en particular, superada por la constatación de que ni siquiera podía salir de la habitación sin pedirme ayuda con su silla de ruedas, agarró la caja de pañuelos y, uno por uno, hizo trizas cada pañuelo sobre la alfombra. ¡Fue un acto de desafío que no requirió mi cooperación! Es lo que ella esperaba. Saborearía la impotencia, llamándome "CFC", que luego supe que era un término utilizado por algunas personas discapacitadas para designar al "cuerpo físicamente capaz". Acentuó la palabra temporalmente, expresando el deseo de que, algún día, yo entendería su humillante posición desde mi propia experiencia al respecto. (S. Buechler, 2019, p.136)

Nunca debemos subestimar los peligros del orgullo herido, los sentimientos de humillación, la vergüenza y cómo afectan a las personas e incluso a las naciones. Esta es una de mis propias declaraciones sobre el tremendo potencial destructivo de estos sentimientos. 
En cierto sentido, las personas mueren de vergüenza todos los días. Están dispuestas a matar o morir ellas mismos porque alguien insultó a su familia, a su país o a su religión. Se suicidan en lugar de enfrentar la vergüenza de la bancarrota, el fracaso en la escuela, el trabajo o el amor. Se suicidan cuando un acosador amenaza con exponer sus vergonzosos secretos. Algunos de nosotros nos tomamos nuestro tiempo muriendo de vergüenza, extendiéndolo a lo largo de la vida, mientras que otros salen abruptamente, pero morir de vergüenza es tan antiguo como la humanidad. (Buechler, 2015, p.45)

A menudo he pensado que uno de los objetivos del tratamiento puede ser facilitar la capacidad del paciente de valorar la vida por encima del orgullo. En esta forma de pensar, quiénes somos es más importante que cómo nos vemos. La calidad de nuestras relaciones y el significado de nuestros legados deberían ser más importantes que la forma en que nos vemos en los ojos de los demás. (S. Buechler, 2019, p.139)

Los pacientes observan cómo vivimos las sesiones, y a veces descubren cómo quieren ser, o cómo no quieren ser. Un ejemplo sería cómo reaccionamos a los momentos en los que podríamos sentirnos avergonzados. Estos casos llevan el tema de la vergüenza a un enfoque más sutil.

Los pacientes a menudo tratan de leer nuestros valores a partir de nuestro comportamiento en las sesiones. Por ejemplo, cuando elegimos revelar algo, los valores que nos llevan a hacerlo pueden ser tan importantes para el paciente como la revelación en sí misma. Otro ejemplo de que nuestros valores tienen un impacto en el paciente es que cuando estamos implicados en el trabajo, y demostramos que la ayuda a este paciente es significativa para nosotros, esto puede elevar la autoestima del paciente. Creo que el paciente debe inspirarse en un analista que ejerce esfuerzo y a veces está dispuesto a asumir riesgos interpersonales en beneficio del tratamiento.

En el capítulo 8, abordo la cuestión del perdón. En aras de respetar el tiempo, sólo comentaré brevemente este tema. Por lo general se asume que el perdón es saludable, y muy a menudo lo es, pero creo que es importante reflexionar sobre si el perdón será genuino, y sobre para quién sería el perdón, quién es el que perdona y quién es el que es perdonado. Si es para el que es perdonado, entonces es relevante la cuestión de si esa persona merece ser perdonada. Pero si creemos que perdonar es más saludable para quien pide el perdón, entonces puede que no sea relevante si el perdonado lo merece. También es posible a veces tener tanto miedo de parecer que perdonamos que nos mantenemos más alejados del otro de lo que realmente nos sentimos que estamos. Por ejemplo, en el trabajo con parejas, una persona puede rechazar todo contacto porque no quiere que la otra se sienta perdonada. 
Pero el resultado de esto puede ser que nunca lleguen a un entendimiento. Se me ocurrieron cuestiones sobre el perdonar cuando leí un libro sobre analistas que pasaron por experiencias en campos de concentración durante la segunda guerra mundial, "Alimentado con lágrimas", (Ehrlich, y cols.) Por ejemplo, ¿cuál es nuestra creencia sobre el alcance y las limitaciones de la responsabilidad individual? ¿Son los hijos de los nazis de alguna manera responsables? En un momento del libro, un analista alemán pidió ser perdonado por la guerra y se le dijo que reconocieron su deseo de ser perdonado, pero eso es todo lo que podían hacer. Algunas cosas no pueden ser perdonadas. En general, sugiero que perdonar es algo que surge bastante en el trabajo clínico, por lo que es importante que los clínicos reflexionemos sobre nuestras propias actitudes.

En el siguiente capítulo, capítulo 9, planteo algunas preguntas sobre el lugar del sufrimiento en nuestra vida y detallo algunos de mis propios puntos de vista. Nuestra sociedad tiene actitudes confusas sobre el sufrimiento de los demás, congregándose en torno al mismo a modo de entretenimiento, pero mirándolo de lejos en la calle o el metro. Reverenciamos al enfermo que no se queja, pero sin embargo en los "reality" de la televisión recompensamos a los que lo dicen todo. Creo que el resultado es confusión. La gente a menudo tiene la impresión de que el sufrimiento es una interrupción de la vida que se suponía que eran capaces de construir. Se sienten poco preparados y avergonzados ante su dolor.

¿Por qué las víctimas a menudo sienten vergüenza por lo que han soportado? Aquellos que sufren de depresión también a menudo sienten vergüenza, como si hubieran fallado en la vida. La vergüenza puede ser un verdadero problema en el tratamiento, ya que a menudo es la emoción que obstaculiza el trabajo con el resto de las emociones. He estudiado tres actitudes sobre el sufrimiento. A veces ha sido visto como un síntoma que debemos tratar de reducir inmediatamente, o algo inevitablemente humano que debemos aprender a soportar, o una fuente potencial de sabiduría de la que debemos tratar de aprender. Creo que nuestras propias actitudes sobre este tema afectarán nuestro trabajo con los pacientes. Afectará a lo que nos enfocamos, lo que recordamos, y, especialmente, cómo trabajamos con las defensas del paciente. ¿Las vemos como aliadas si protegen al paciente del sufrimiento, o como problemas en sí mismos?

En términos más generales, ¿creemos que no siempre es saludable adaptarnos a circunstancias dolorosas, como Fromm y May, mientras que, para Sullivan, adaptarse bien fue un signo de salud? Para tomar una situación extrema, ¿cuál es la forma más saludable de vivir con la terrible enfermedad que se conoce como ALS? ¿Deberíamos ceder o tratar de luchar por cada hora normal? ${ }^{1}$ 
¿Cómo afectan los distintos tipos de pérdida al sentido de sí mismo? ¿Hay maneras de generalizar sobre esto? ¿La pérdida de memoria nos afecta a todos de manera diferente al perder la capacidad de caminar? ¿O la pérdida de cada persona es significativa de una manera que es particular a ese individuo? Cuando nos defendemos de la conciencia de nuestras pérdidas, ¿eso siempre nos aleja inevitablemente de nosotros mismos y causa más pérdidas?

En términos más generales, ¿cuál es el precio de varios patrones de defensa, cuando nos enfrentamos a enfermedades, pérdidas, sufrimientos? Por ejemplo, si hemos confiado en el control obsesivo, ¿qué sucede cuando la enfermedad hace que nuestros cuerpos queden decididamente fuera de nuestro control? Creo que la forma en que tendemos a lidiar con la vida antes de la pérdida afecta profundamente a la forma en que la soportamos.

Algunos filósofos, escritores y analistas focalizan su trabajo en cómo dejar que el sufrimiento nos cambie y nos permita crecer. Por otro lado, algunos se aferran como a una victoria a su viejo Self, a cómo éramos antes de la enfermedad o del envejecimiento. ¿Cómo entendemos cada uno la salud?

¿Debemos dejar que el sufrimiento nos cambie? Otra pregunta es si ayuda encontrar palabras para el dolor. Tal vez a veces nos hace sentir más competentes. En términos más generales, creo que tener un rico vocabulario para la emoción mejora nuestra autocomprensión. Por ejemplo, distinguir el miedo de la ansiedad nos ayuda a recoger y aprender de los momentos de cada uno de ellos.

Permanecer como tu self observador cuando sufres de una enfermedad terrible parece algo vital, pero ¿qué pasa si eso lleva a hacer observaciones sobre tus pérdidas que rompen tu corazón?

Veo el sufrimiento como moldeado por el equilibrio de los otros sentimientos que ocurren al mismo tiempo. A veces puede ser suavizado por el amor, la alegría, (que entiendo como el "antídoto universal" a toda emoción negativa, Buechler, 2008) la esperanza, el coraje, la curiosidad, o el sentido de propósito, pero el sufrimiento puede ser también más problemático cuando se acompaña de sentimientos negativos, como el arrepentimiento, la vergüenza y la rabia.

Generalmente, creo que es difícil aliviar directamente el dolor, pero podemos ser capaces de ayudar a los pacientes a ponerse en contacto con sentimientos positivos que también están potencialmente presentes. Un apego inquebrantable a la propia identidad puede ser parte 
de lo que puede ayudar, así como un sentido de propósito, amor y una habilidad para escapar del momento presente en los sueños.

Una pregunta que creo que es relevante cuando estamos tratando de ayudar a alguien que sufre es- ¿Puede el uso de ciertas defensas ayudar a los seres humanos a enfrentar los desafíos particulares bien, o lo suficientemente bien? ¿Necesitamos la negación, en algunas circunstancias, y estamos mejor provistos con ella? Ciertamente también es verdad que algunas defensas nos obstaculizan en algunas situaciones altamente desafiantes. La persona altamente obsesiva a menudo no puede tomar descanso de pensar en algo perturbador. Mi apuesta es que una capacidad de uso moderado de todas las defensas, en lugar de la dependencia excesiva de una, nos equipa mejor. Pero creo que esta es una cuestión importante que los analistas deben considerar.

Termino esta discusión del capítulo 9 mencionando un ejemplo de emoción positiva que altera el sufrimiento. Paul Kalanithi (2016), un doctor que murió a una edad muy temprana, escribió el libro extremadamente conmovedor, "El buen doctor"2. De alguna manera fue capaz de dejar que el amor por los que lo rodeaban alterara su sufrimiento, y escribió conmovedoramente sobre su experiencia, en parte para dejar algo que su hija pudiera leer cuando creciera. No hay duda, tal y como yo lo entiendo, que el amor le permitió preservar este grado de equilibrio emocional.

El capítulo 10, último capítulo de esta obra, trata de la formación. ¿Cómo nutrimos la capacidad del clínico para inspirar la salud en los pacientes? En este capítulo escribo sobre mi propia formación y doy algunas sugerencias para el futuro.

Como ya he mencionado, tres analistas, Sullivan, Fromm y Fromm-Reichmann influyeron mucho en mis maestros, supervisores y analistas. En mi mente desarrollé un diálogo con cada uno de los tres. Mi "Sullivan personal" hizo su aparición cuando comenzaba mis estudios de graduación. Me enseñaron a prestar especial atención a los cambios de ansiedad (ya sea en el paciente o el analista). He ampliado esta idea al incluir el intentar percibir los cambios en todas las emociones fuertes en la sesión que tanto yo como el paciente manifestamos. Durante toda mi carrera profesional desarrollé una perspectiva sobre el lugar del tratamiento. Creo que la vida es realmente lo que cura a la gente, pero el tratamiento puede hacer que más vida sea posible.

Creo que es natural que los clínicos que aún son principiantes quieran sentir que saben lo que están haciendo, cuando se enfrentan a las necesidades / deseos / demandas de los pacientes. Pero un conjunto de reglas tiene escollos: reduce la complejidad del momento vivido. No podemos prescindir de alguna guía, pero la formación por la que abogo se centra en los 
dilemas inherentes a la condición humana - por ejemplo, ¿cuánto hemos de adaptarnos a las circunstancias de la vida vs. luchar para cambiar lo que sentimos que está mal?, ¿cómo lidiar con los sentimientos intensos, y en qué medida ponerlos en palabras. Si el paciente y el analista provienen de una cultura muy similar, es posible que ambos no se den cuenta de las suposiciones sobre ser saludable que tenemos en común. Por ejemplo, si mi paciente y yo nos aculturamos para creer que las esposas siempre deberían hacer que sus esposos se sientan cómodos, tal vez ni siquiera reconozcamos que estamos haciendo esa suposición.

En términos más generales, creo que es especialmente importante que los clínicos seamos conscientes de nuestros propios patrones defensivos, así como de nuestros sesgos culturales, ya que estos podrían crear puntos ciegos. Ninguna teoría puede prepararnos adecuadamente para nuestra tarea, aunque las teorías pueden darnos alguna orientación. Pero nada sustituye a nuestro propio análisis.

Pero mi creencia más fuerte es que cada persona en su formación necesita llegar a ser el mejor instrumento terapéutico que sea capaz de ser. Para ello es necesario aprender sobre la condición humana y el carácter de todos los que nos tienen algo que decir al respecto, incluyendo filósofos, artistas, grandes escritores de ficción, poetas, y otros.

Los maestros que más me ayudaron fueron los que vivían en voz alta. Compartieron su pensamiento, lo que me ayudó a aclarar el mío, y mostraron un proceso auto-reflexivo.

El valor de la verdad y la importancia vital de la integridad son valores cruciales que debemos transmitir en la formación. La comodidad con lo contradictorio también es esencial. Tenemos que enfrentar el enigma post moderno de que somos inherentemente subjetivos, y aún así, tener fe en nuestras propias percepciones. Nuestro foco es selectivo, pero los pacientes merecen tener un espacio en el que encontrar sus propias respuestas. El proceso creativo en el tratamiento a veces requiere que tengamos el valor de expresarnos a medida que nuestros pensamientos están siendo formulados. Con frecuencia descubrimos la interpretación según la estamos diciendo. ¿Cómo ayudamos a los candidatos a desarrollar ese valor? Para ello, creo que los clínicos necesitan tener fe en nuestras motivaciones, en su mayoría no hostiles. Necesitamos humildad, conciencia de nuestras propias imperfecciones, pero también, así lo siento, algunos (valores) absolutos. Para mí incluyen que el tratamiento puede alterar una vida, que es posible cambiar el pasado comprendiéndolo de manera diferente, que damos a nuestras experiencias sus significados, que estamos aquí (en la tierra) para elegir la vida, y que cada uno necesita un sentido claro de propósito. Los clínicos siempre serán, necesariamente, neutrales y (a la vez) defensores de un punto de vista sobre la 
condición humana. Debemos ayudar a los candidatos a aceptar esta verdad contradictoria y paradójica.

\section{REFERENCIAS3}

Buechler, S. (2012). Déficits de autoestima en una sociedad cambiante. Clínica e Investigación Relacional, 6 (1): 52-55.

Buechler, S. (2012). Still practicing. The heartaches and joys of a clinical career. New York: Routledge

Buechler, S. (2013). El Psicoanálisis Interpersonal tal como yo lo veo. Cap.12 (pp. 497-541) en la obra de A.Avila (Ed.) La tradición interpersonal. Perspectiva social y cultural en Psicoanálisis. Madrid: Ágora Relacional.

Buechler, S. (2015). Marcando la diferencia en las vidas de los pacientes. Experiencia emocional en el ámbito terapéutico. Madrid: Ágora Relacional. [V. original: Making a difference in patients' lives. New York: Routledge, 2008]

Buechler, S. (2015a). Desarrollando mi enfoque terapéutico. Clínica e Investigación Relacional, 9 (2): 335-344.

Buechler, S. (2015b). La alegría, la vergüenza, el arrepentimiento y la tristeza en la terapia.Clínica e Investigación Relacional, 9 (2): 345-357.

Buechler, S. (2016). Creatividad en la Poesía y en el Psicoanálisis. Clínica e Investigación Relacional, 10 (3): $763-769$.

Buechler, S. (2017). Inspirada por Erich Fromm. En Hacia Una Ciencia Humana: La Relevancia de Erich Fromm en La Actualidad. ed. Rainer Funk \& Neil McLaughlin, Mexico: Demac, 2017, pp. 187-200.

Buechler, S. (2018). Valores de la Clínica. Emociones que guian el tratamiento psicoanalítico. Madrid: Ágora Relacional [v. Original: Clinical values: Emotions that guide psychoanalytic treatment. Hillsdale, NJ: The Analytic Press, 2004]

Buechler, S. (2018). Psychoanalytic Reflections. Training and Practice. IPBooks.

Buechler, S. (2019). Comprendiendo y tratando a pacientes en psiconalísis clínico. Lecciones desde la literatura. Madrid: Ágora Relacional. [V. original: Understanding and treating patients in Clinical Psychoanalysis. Lessons from literature. New York: Routledge, 2015]

Buechler, S. (2019). Historias breves y Poesía que inspiran mi trabajo (a propósito de la presentación de "Valores de la Clínica", $2^{a}$ ed. Castellana). Clínica e Investigación Relacional, 13 (1): 11-21.

Buechler, S. (2019). Las emociones en la práctica clínica con un caso ilustrativo. Clínica e Investigación Relacional, 13(1): 32-43.

Buechler, S. (2019). Psychoanalytic approaches to problems in living. Addressing life's changes in clinical practice. New York: Routledge

Buechler, S. (2019). Una autobiografía psicoanalítica. Clínica e Investigación Relacional, 13 (1): 44-64. 
Buechler, S. (2019). Valores de la Clínica. Una invitación a saborear la vida. Clínica e Investigación Relacional, 13 (1): 22-31.

Buechler, S. y Ávila, A. (2013). La formación y la supervisión desde la perspectiva interpersonal y sociocultural. Cap.13 (pp. 543-594) en la obra de A.Avila (Ed.) La tradición interpersonal. Perspectiva social y cultural en Psicoanálisis. Madrid: Ágora Relacional.

Original recibido con fecha: 3/2/2020 Revisado: 28/02/2020 Aceptado: 15/03/2020

NOTAS:

${ }^{1} \mathrm{~N}$. de T: ALS Esclerosis lateral amiotrófica

${ }^{2} \mathrm{~N}$. de T. El título original es "Cuando el aliento se convierte en aire". Esta obra ha sido traducida al castellano: Kalanithi, P. (2016) El Buen Doctor. México: Océano

${ }^{3} \mathrm{~N}$. de T.: Se han incluido aquí las principales referencias de sus obras, y especialmente las que están publicadas en castellano. 